Cómo citar este artículo en Chicago: Molano Osorio, Ingrid Vanessa. “Signos cardinales de Libia Posada y En el brazo del río de Marbel Sandoval: narrativas cartográficas sobre los cuerpos del desplazamiento forzado”. Escritos 30, no. 64 (2022): 25-40.

doi: http://doi.org/10.18566/escr.v30n64.a02

Fecha de recepción: 29.07 .2021

Fecha de aceptación: 13.12 .2021

\title{
Signos cardinales de Libia Posada y En el brazo del río de Marbel Sandoval: narrativas cartográficas sobre los cuerpos del desplazamiento forzado ${ }^{*}$
}

\author{
Cardinal signs, by Libia Posada and In the arms of the river, by Marbel Sandoval: \\ cartographic narratives on the bodies of forced displacement
}

\author{
Ingrid Vanessa Molano Osorio ${ }^{2}$
}

\section{RESUMEN}

El cuerpo como objeto de la violencia generada en el marco del conflicto armado colombiano ocupa un lugar central en distintas obras de arte y literarias del país. En diversos casos, tal centralidad se debe al compromiso de los autores por resignificar la ocurrencia de masacres, secuestros, desapariciones o desplazamientos forzados, los cuales involucran o recaen sobre los cuerpos de las víctimas. Este es el caso de las obras analizadas de forma comparativa en este artículo: la instalación Signos cardinales de Libia Posada y la novela En el brazo del río de Marbel Sandoval, pues ambas confluyen en la resignificación del cuerpo en el contexto del desplazamiento forzado. Entre los objetivos, se busca delimitar la manera como se configura una narrativa de carácter cartográfico en las obras. También se pretende reflexionar sobre la relación entre el cuerpo-desplazamiento forzado: interno y transfronterizo. El análisis aquí planteado gira en torno al concepto de narrativa cartográfica, que será estudiado a partir, por un lado, de Italo Calvino, quien define la cartografía como unión espacio temporal articulada en la idea de itinerario; por el otro, de Michel de Certeau, ya que considera las estructuras narrativas, implícitas en la cartografía, en cuanto sintaxis espaciales, noción que permite analizar la representación del desplazamiento forzado que se realiza en las obras como delimitación simbólica de itinerarios reordenadores del espacio.

1 Este artículo se deriva de Ingrid Vanessa Molano Osorio, "Signos cardinales de Libia Posada y En el brazo del río de Marbel Sandoval: La resignificación del cuerpo a través de una narrativa cartográfica” (tesis de maestría, Universidad de los Andes, 2019), https://repositorio.uniandes.edu.co/handle/1992/48459.

2 Magíster en Literatura por la Universidad de los Andes, Colombia. Profesional en Estudios Literarios por la Universidad Pontificia Bolivariana, Colombia. Médico y Cirujano por la Universidad de Antioquia, Colombia. Correo electrónico: inngridvanne@gmail.com 
Palabras clave: Cuerpo; Espacio; Narrativa; Cartografía; Resignificación; Signos cardinales; En el brazo del río; Libia Posada; Marbel Sandoval; Desplazamiento forzado.

\begin{abstract}
The body as an object of the violence generated in the framework of the Colombian armed conflict occupies a central place in different works of art and literature in the country. In various cases, such centrality is due to the commitment of the authors to resignify the occurrence of massacres, kidnappings, disappearances or forced displacement, which involve or fall on the bodies of the victims. Such is the case of the works analyzed comparatively in this article: the installation Signos cardinales (or Cardinal signs) by Libia Posada and the novel En el brazo del río (or In the arms of the river) by Marbel Sandoval. Both of these works converge in the resignification of the body in the context of forced displacement. Among the objectives, it seeks to define the way in which a cartographic narrative is configured in the works. It is also intended to reflect on the relationship between the body and forced displacement: internal and crossborder. The analysis proposed here revolves around the concept of cartographic narrative, which will be approached from, on the one hand, Ítalo Calvino, who defines cartography as a space-time union articulated in the idea of itinerary; and on the other, by Michel de Certeau, since he considers the narrative structures, implicit in cartography, as a spatial syntax, that is, a notion that allows us to address the representation of forced displacement as a symbolic delimitation of reordering itineraries of space.
\end{abstract}

Keywords: Body; Space; Narrative; Cartography; Resignification; Signos cardinales; En el brazo del río; Libia Posada; Marbel Sandoval; Forced displacement.

$\mathrm{P}$ ensadores como Walter Benjamin le han adjudicado al arte un sentido político, al considerar necesario el distanciamiento entre las prácticas artísticas y los intereses de regímenes como el fascismo, pues serían aprovechadas para estetizar la guerra a través de conferirle una apariencia bella, como lo hace el futurismo, y de esta forma, en vez de repulsión, provocar su disfrute, entre cuyas consecuencias se encuentra la espectacularización de la violencia. ${ }^{3}$ De ahí el llamado de Benjamin por un arte de carácter revolucionario, capaz de despertar la conciencia crítica en sus espectadores, lo cual llevaría a la politización del arte como una manera de responder a la estetización de la violencia. ${ }^{4}$

Es que el dominio de la estética por entes estatales con fines políticos bien puede entenderse como "un síntoma y un agente de dominación [...]; una sujeción mediada a esos poderes económicos y burocráticos

3 Tal espectacularización sería una de las consecuencias del fenómeno que Walter Benjamin denomina estetización de la política, entre cuyos principales gestores se encuentra el fascismo, régimen que convierte la guerra en un "nuevo objeto de fascinación y contemplación estética cuya nubosidad hipermediática hizo que se desvaneciera el espacio de toda crítica”; cf. Miguel Gutiérrez Peláez y Flor Ángel Rincón, “Trayectos entre estética y biopolítica: Trauma, sujeto e imagen", (pensamiento), (palabra) y obra, no. 7 (2012): 47. Es que "Benjamin ya nos advierte cómo en los discursos fascistas la guerra se exalta desde una 'desinhibida traducción' a esta de los principios del arte por el arte, al ritualizarla desde valores de culto. La guerra se transforma en una 'forma pura' [...], en una fuente de vida eterna que permite expresar, como en un gran espectáculo dramático, impulsos heroicos y tener las 'experiencias más grandiosas y aterradoras". Así, "la guerra se convierte [...] en una forma de expresión y de experiencia vital de la subjetividad, hasta el punto en que la destrucción y la violencia pueden experimentarse en términos de placer estético"; cf. María del Rosario Acosta y Laura Quintana, "De la estetización de la política a la comunidad desobrada", Revista de Estudios Sociales, no. 35 (2010): 55.

4 Walter Benjamin, La obra de arte en la época de su reproductibilidad técnica, trad. por Andrés E. Weikert (México: Ítaca, 2003), 101. 
que por su constitución ocultan sus formas de dominio". ${ }^{5}$ Por tanto se incita al arte para que haga reconocible dichas formas de dominio "subvirtiendo sus propios impulsos estéticos", reemplazar la belleza, la práctica del arte de lo bello, por la del arte de lo grotesco, de lo abyecto, capaz de emitir gestos, voces, imágenes, relatos que permitan señalar, testificar e, incluso, denunciar, entre otras, las múltiples formas de violencia que se ciernen sobre la población en contextos bélicos propiamente dichos o la subyugación proferida por cuestiones de raza, identidad sexual o con fines consumistas; de lo que se trata no es de cambiar la realidad a través del arte o la literatura, sino de abrir espacios de reflexión y posibilitar nuevos ángulos de visión que favorezcan ese despertar del sentido crítico de sus espectadores/lectores.

Este llamado es todavía vigente en el contexto de la confrontación armada colombiana, durante la cual se han configurado diversas prácticas de violencia que terminan impactando en la mayoría de los casos a la población civil, sometida al despojo, obligada a desplazarse, víctima de masacres, desapariciones u otras violencias corporales. En este marco, el cuerpo se ha constituido en objeto de la punición y control, para ejercer dominio sobre algunas regiones del país, debido, sobre todo, al interés por la tierra para fines económicos y delictivos, como la minería ilegal o los cultivos ilícitos. En la confrontación armada colombiana, como en otras guerras contemporáneas, la población civil se constituye en "el campo de gravedad"7 y los cuerpos en sí mismos en "nuevas dimensiones espaciales del poder", al ser objeto de la violencia, en muchos casos extrema. Esto va en consonancia con Foucault, quien considera que "las relaciones de poder penetran en los cuerpos", de ahí que el cuerpo pueda ser comprendido como "un espacio específico donde se vive y se transmite el poder", ${ }^{10} \mathrm{y}$ así resaltar la dimensión política que posee.

En este contexto, múltiples artistas y escritores colombianos trabajan por la resignificación del cuerpo, de las memorias y de las voces de quienes han padecido las consecuencias de la prolongada confrontación armada. Algunos de ellos han direccionado su quehacer a través de preguntas por la indiferencia que pareciera imperar en algunos sectores ante la violencia, el destino último de los desaparecidos, la situación de abandono propia de muchos desplazados, la deshumanización del conflicto armado o la victimización que, incluso, sufre la tierra.

Entre estos autores se encuentran la artista Libia Posada con la instalación Signos cardinales (2008) y la escritora Marbel Sandoval con la novela En el brazo del río (2006), cuyas respectivas obras coinciden en la representación del desplazamiento forzado. En el primer caso, se trata de las fotografías de las piernas de doce mujeres víctimas de este tipo de violencia, con los mapas de las rutas que cada una recorrió. En el segundo, se recrea la masacre ocurrida en la vereda santandereana Vuelta Acuña en 1984, la desaparición

5 Peter Fenves, “¿Existe una respuesta a la estetización de la política?”, en Walter Benjamin: Culturas de la imagen, compilado por Alejandra Uslenghi (Buenos Aires: Eterna Cadencia, 2010), 85.

6 Fenves, “¿Existe una respuesta a la estetización de la política?”, 85.

7 Elsa Blair “¿Nuevas guerras? ¿Nuevos espacios para la guerra? O ¿Nuevas espacialidades?”, en (Des) territorialidades y (no) lugares: Procesos de configuración y transformación social del espacio, ed. por Diego Herrera Gómez y Carlo Emilio Piazzini Suárez (Medellín: La Carreta, 2006), 139.

8 Blair, “¿Nuevas guerras?”, 143.

9 Elsa Blair, "La política punitiva del cuerpo: 'Economía del castigo' o mecánica del sufrimiento en Colombia”, Estudios Políticos, no. 36 (2010): 42.

10 Blair, "La política punitiva del cuerpo", 42. 
de una de las víctimas y el subsecuente éxodo de campesinos. La novela lleva implícitas preguntas como ¿quiénes eran las personas acribilladas y cuáles sus historias de vida?, ¿en qué condiciones vivían los desplazados en la ciudad de llegada? o ¿qué pudo haber pasado con el cuerpo perteneciente a la única persona desaparecida? Del mismo modo, en la instalación, se indaga el abandono del hogar, por el tránsito constante de un lugar a otro o por el carácter no tanto poroso sino móvil de las fronteras, llevadas a cuestas por las personas desplazadas mientras recorren el país, donde abundan "paisajes de miedo", ${ }_{11}$ como pueden ser las fosas comunes, los pueblos desolados o los ríos convertidos en cementerios líquidos, producto de las prácticas de violencia, cuyo objetivo es generar terror en las comunidades como estrategia de guerra y con fines de apropiación territorial. ${ }^{12}$ Es que la configuración de las obras responde a una mirada crítica interesada en cuestionar e, incluso, denunciar los órdenes establecidos por la guerra. En el desplazamiento forzado, dichos órdenes implican para las víctimas que su cuerpo se constituya, subjetiva y simbólicamente, en espacio, centro y certeza de la existencia, debido al abandono del hogar al que se ven sometidas, condición que a la vez afecta las dimensiones física y simbólica de la existencia.

Así es como, a través de un análisis comparativo, se plantea que en la instalación y en la novela se establece una relación cuerpo-espacio, mediante la cual se trasciende la representación del cuerpo como espacio de la punición, debido a que ambas narrativas se tejen alrededor no tanto de las huellas físicas dejadas por la violencia, sino de la construcción de sentido a partir de experiencias límite de sufrimiento. En las obras, por tanto, el cuerpo se erige como espacio simbólico de significación y se transmuta en expresión de resistencia contra el olvido o el acallamiento pretendido por medio de la violencia.

De igual manera, se va a considerar que en ambas puestas artísticas se estructura una narrativa de carácter cartográfico, comprendida desde el punto de vista de la delimitación de itinerarios o prácticas ordenadoras del espacio, es decir, con valor de "sintaxis espaciales", ${ }^{13}$ lo cual permite entender la demarcación de recorridos llevada a cabo en las obras como ejercicio de reordenación e, incluso, reconstrucción simbólica de determinadas regiones del país señalizadas con la impronta de la violencia fruto del conflicto armado. A través de tal delimitación, en las obras se reconstruye el que puede llamarse texto social del desplazamiento forzado y otros tipos de violencia corporal.

La reconstrucción simbólica del mencionado texto social de la violencia también responde a la mirada crítica de las respectivas autoras, debido, entre otras razones, a que las regiones cartografiadas en ambas obras en su mayoría resguardan determinados pasajes de la historia del conflicto armado colombiano, que incluyen rutas indicativas de la migración forzada hacia el extranjero, así como lugares convertidos en fosas comunes donde se ha ido desechando el sinnúmero de cadáveres producidos por la guerra en el país, entre los que se encuentran ríos como el Magdalena o el Cauca. De tal reconstrucción resultan mapas alternos, delineados en los itinerarios emprendidos por los desplazados representados en cada obra.

11 Ulrich Oslender, "Des-territorialización y desplazamiento forzado en el Pacífico colombiano: La construcción de 'geografías de terror'", en (Des) territorialidades y (no) lugares: Procesos de configuración y transformación social del espacio, ed. por Diego Herrera Gómez y Carlo Emilio Piazzini Suárez (Medellín: La Carreta, 2006), 161.

12 Oslender, "Des-territorialización y desplazamiento forzado en el Pacífico colombiano", 161.

13 Michel de Certeau, La invención de lo cotidiano. Vol. 1: Artes de hacer. Traducido por Alejandro Pescador (México: Universidad Iberoamericana, 2000), 127. 


\title{
La relación cuerpo-espacio: un vínculo entre lugar y territorialidad
}

\begin{abstract}
Nuestro existir es siempre un "estar en" y ese "estar en" es estar en el espacio, en algún espacio. Y las diferentes maneras de existir son para empezar diferentes maneras de estar en el espacio. El hecho de que nuestra existencia sea forzosamente espacial tiene, sin duda, que ver con el hecho de que somos cuerpo(s), de que ocupamos lugar. Pero ocupar lugar es solo posible porque hay un lugar que ocupar, nuestro cuerpo mismo es espacio, espacialidad de la que no podemos liberarnos.
\end{abstract}

Elsa Blair

¿Por qué cuerpo-espacio y no cuerpo-lugar o cuerpo-territorio? Para la definición de este vínculo, se tuvieron en cuenta dos consideraciones. La primera tiene que ver con el cuerpo en sí mismo en su condición de espacio vital, es decir, como precondición de la existencia. La segunda se relaciona con la reformulación contemporánea de la noción de espacio, el cual pasa, de ser considerado simple escenario para los diversos acontecimientos históricos, políticos o sociales, a concebirse como una dimensión que desempeña un papel en estos acontecimientos, pues "hace parte integral e interviene activamente en la constitución de las expresiones, prácticas y procesos [...] de una sociedad". ${ }^{14}$ Esta postura se encuentra en consonancia con la de Doreen Massey, quien considera el espacio una dimensión relacional, abierta y múltiple. A grandes rasgos, esto alude a la potencialidad que tiene el espacio de ser re-construido a partir de la interacción social, ${ }^{15}$ así como a la influencia que ejerce el mismo espacio en el desarrollo de la sociedad ${ }^{16} \mathrm{y}$ al carácter inacabado de los procesos y de las prácticas llevadas a cabo en su seno, razón por la cual se trata de procesos dinámicos y abiertos a la transformación. Para Massey, el lugar es un espacio localizado y concreto, como puede ser una ciudad o un barrio, aunque no por eso cerrado, pues, en tanto espacio que es, posee un carácter "híbrido [...] que siempre tiene vínculos con el resto del mundo". ${ }^{17}$

De las posturas señaladas, se adaptan las ideas de apertura y transformación en la relación cuerpoespacio propuesta. Así pues, se parte de considerar el cuerpo como espacio en sí mismo, en el cual se articula la dimensión de lugar, dada por su materialidad, por su condición de soporte orgánico, físico y psíquico de la existencia, así como la de territorialidad, en los términos formulados por Carlo Emilio Piazzini Suárez, quien la considera "como un proceso de espacialización de las relaciones de poder [...], que puede incorporar prácticas de espacialización [de tales relaciones] sobre los saberes, las técnicas e inclusive los cuerpos". ${ }^{18}$ Es decir, que las prácticas de espacialización conllevan formas de apropiación y significación del territorio, ${ }^{19}$ por ende, puede decirse que la noción de territorialidad alude a la posibilidad de reconstrucción continua del territorio, usualmente considerado "entidad física previamente dada sobre la cual una entidad política, notablemente el Estado, ejerce su autoridad". ${ }^{0}$ Hablar de territorialidad

14 Carlo Emilio Piazzini Suárez, "El tiempo situado: Las temporalidades después del 'giro espacial"', en (Des) territorialidades y (no) lugares: Procesos de configuración y transformación social del espacio, ed. por Diego Herrera Gómez y Carlo Emilio Piazzini Suárez (Medellín: La Carreta, 2006), 68.

15 Doreen Massey, "Espacio, lugar y política en la coyuntura actual”, Urban, Revista del departamento de urbanística y ordenación del territorio no. 4 (2012): 9.

16 Massey, "Espacio, lugar y política en la coyuntura actual", 8.

17 Massey, "Espacio, lugar y política en la coyuntura actual", 9.

18 Piazzini, "El tiempo situado", 69.

19 Blair, “¿Nuevas guerras?”, 150.

20 Piazzini, "El tiempo situado", 69. 
implica entonces desestabilizar el carácter preconcebido y el sentido de fijeza adjudicados al territorio. De este modo, puede establecerse una relación de correspondencia entre el carácter constructivo adjudicado a la noción de territorialidad con el cuerpo. Tal correspondencia se observa, por ejemplo, en la incidencia de los discursos médicos, teológicos, biopolíticos o racistas en la modelación de los cuerpos con fines regulatorios, a partir de los cuales se han configurado algunas prácticas que condicionan la cotidianidad y el estilo de vida de las personas, como uno de los resultados de los procesos de espacialización del poder sobre los cuerpos. En el conflicto armado colombiano, tal espacialización se lleva a cabo a través de unas prácticas de violencia corporal, como el desplazamiento forzado, la masacre, la tortura o el abuso sexual. A su vez, la dimensión de territorialidad confiere un carácter político a la relación cuerpo-espacio y la vincula con la tierra; además, permite considerar el cuerpo como "escenario de reconocimiento", ${ }^{21}$ por eso mismo, soporte para los procesos identitarios, que suponen la idea de reconstrucción. La noción de territorialidad también permite comprender el cuerpo como espacio simbólico sobre el cual se espacializa otro tipo de prácticas, por ejemplo, las de carácter artístico llevadas a cabo en la instalación y en la novela analizadas, cuya articulación se deriva de dos formas de explorar, interpretar y cuestionar algunos tipos de violencia, mediante una narrativa cartográfica.

\section{Signos cardinales y En el brazo del río: dos sistemas comunicativos espacializantes y una narrativa cartográfica}

Cuando se viaja es usual que el viajero determine previamente una ruta a seguir [...] Viajar por la fuerza implica, sin embargo, inaugurar caminos o descubrir rutas urgentes difíciles de localizar, reconocer, comprender y ver, no solo en la memoria de los que huyen, sino en esa representación del territorio, denominada mapa, el cual implica [...] una serie de prejuicios y exclusiones de lugares y experiencias.

Libia Posada

Según Italo Calvino, la cartografía nace como una "necesidad de resumir en una imagen la dimensión del tiempo junto a la del espacio".22 Y la íntima conjunción espaciotemporal de la que se origina el mapa engendra y "presupone una idea narrativa, está concebido en función de un itinerario, es una odisea"23. A partir de Calvino es posible comprender cómo en ambas obras se despliega una narrativa cartográfica. Por un lado, tanto en la instalación como en la novela, se observa una puesta espacializada. En Signos cardinales, se identifica con facilidad el carácter espacial que posee, debido a la disposición y el montaje de los elementos constitutivos de la obra, por ejemplo, las fotografías, puestas una al lado de la otra sobre un fondo blanco, o las cartografías delineadas sobre lienzos corporales, cual artefactos que expresan por sí mismos el sentido espacial mediante la delimitación de rutas y lugares, representados por diversas convenciones. (Ver Figura 1)

21 Rita Laura Segato, "En busca de un léxico para teorizar la experiencia territorial contemporánea”, en (Des) territorialidades y (no) lugares: procesos de configuración y transformación social del espacio, ed. por Diego Herrera Gómez y Carlo Emilio Piazzini Suárez (Medellín: La Carreta, 2006), 77.

22 Francesco Careri, Walkscapes: El andar como práctica estética, trad. por Maurici Pla (Barcelona: Gustavo Gili, 2002 ), 152.

23 Careri, Walkscapes, 152. 


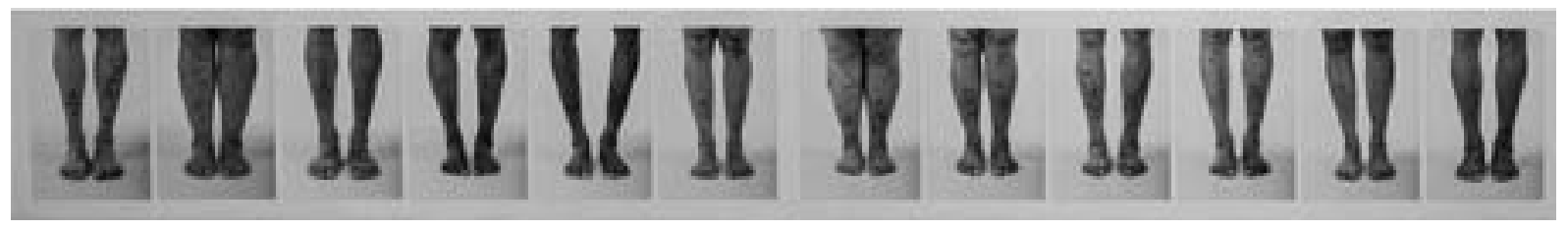

Figura. 1. Imagen de la instalación Signos cardinales

Fuente: Posada, Signos cardinales, 2008. Fotografía. 100 x $80 \mathrm{~cm}$. Red cultural del Banco de la República. https://www. banrepcultural.org/coleccion-de-arte/obra/signos-cardinales-ap4843.

Sin embargo, al poner atención sobre los aspectos formales de la novela, puede verse cómo a través de ellos también se articula un sentido espacial. Entre dichos aspectos, se halla la presencia de dos voces narrativas: Paulina y Sierva María, a la vez personajes de la obra. Este hecho implica el fraccionamiento de la narración y la inclusión de al menos dos puntos de vista alrededor de los acontecimientos constitutivos de la trama. Al menos dos, porque, en algunos apartados, aparecen noticias de prensa en las cuales se expone la versión oficial sobre diversos sucesos de violencia. Así, tales paratextos contribuyen a la configuración del sentido espacializador en la novela. Cabe señalar que solo se hará referencia a las voces narrativas.

Por el otro, esa idea narrativa alojada en el centro de la cartografía se materializa en ambas piezas en la delimitación de itinerarios o "serie[s] discursiva[s] de operaciones", ${ }^{24}$ mediante los cuales se ordena el espacio a medida que se avanza. En los mapas de Signos cardinales, los itinerarios están marcados, como se anotó, por diversas convenciones, entre ellas se encuentran unas líneas punteadas y otras continuas indicativas de la manera en que se lleva a cabo el desplazamiento, a pie, en el primer caso, y a través de medios de transporte como buses, en el segundo. Si se comparan las líneas punteadas con las continuas, puede establecerse un contraste temporal, debido a la mayor velocidad que supone un viaje en un medio de transporte con respecto al que se realiza a pie. Las convenciones que representan lugares de llegada (casas o centros religiosos) ilustran otro tipo de relación espaciotemporal, pues señalan la interrupción, la pausa de los recorridos. (Ver Figura 2)

24 De Certeau, La invención de lo cotidiano, 131. 


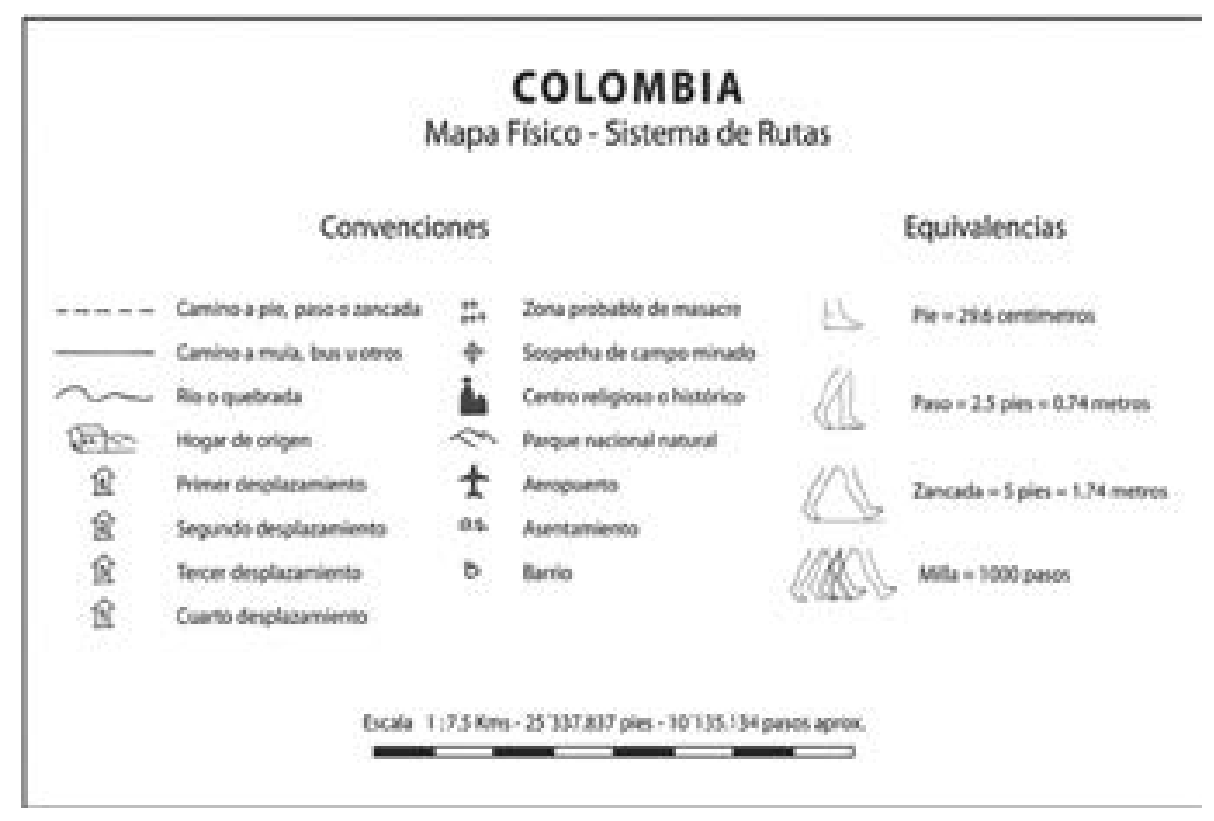

Figura 2. Convenciones

Fuente: Libia Posada, “Signos cardinales”, Cuadernos de música, artes visuales y artes escénicas 9, no. 2 (2014): 222. Fotografía. 100 x 80 cm. https://revistas.javeriana.edu.co/index.php/cma/article/view/13072/10411.

Por su parte, en la novela, algunos de los itinerarios describen la premura de los desplazados ante un hecho amenazador: "Una mañana de diciembre [...] tempraneados empezaron a llegar los vecinos del otro lado de ese brazo del río, venían a pie limpio los maridos con sus mujeres y atrás los pelados [...]. Contaron que en la noche entraron hombres armados por la finca de los Giraldo". ${ }^{25}$ Aunque en la cita no se menciona, la escena se lleva a cabo en la vereda Vuelta Acuña, y el destino será Barrancabermeja, al cual se arriba no por vía terrestre sino fluvial: "A las once de la mañana, luego de bajar por ese río silencioso, nadie hablaba, empezamos a desembarcar en uno de los puertos de Barranca". ${ }^{26}$ Del mismo modo que en la instalación, el entrecruzamiento de las dimensiones espaciotemporales en la novela implica "prácticas organizadoras del espacio", ${ }^{27}$ en medio del caos que suponen hechos como el desplazamiento forzado. En atención a que tales prácticas se llevan a cabo en la realización de los itinerarios, puede decirse que, a partir de ellos, más que cartografiar determinadas regiones, se posibilita su apropiación, significación y reconstrucción, que da como resultado los mencionados mapas alternos.

La idea de ordenación espacial vinculada a la narrativa cartográfica se relaciona con De Certeau, quien propone que "las estructuras narrativas tienen valor de sintaxis espaciales", ${ }^{28}$ cuya función ordenadora es

25 Marbel Sandoval, En el brazo del río (Medellín: Hombre Nuevo, 2006), 24.

26 Sandoval, En el brazo del río, 25.

27 De Certeau, La invención de lo cotidiano, 129.

28 De Certeau, La invención de lo cotidiano, 127. 
llevada a cabo a través de signos no necesariamente lingüísticos, sino que pueden ser de carácter visual, como se observa en las cartografías de la instalación. Es que las cartografías bien pueden considerarse textos no verbales que requieren la decodificación del lenguaje gráfico, dado por líneas, colores o símbolos. ${ }^{29}$ "Como todos los textos, los mapas usan signos para representar el mundo. Los mapas no poseen una gramática en el modo de lenguaje escrito, pero son, sin embargo, textos deliberadamente diseñados, creados por la aplicación de principios y técnicas y desarrollados como sistemas formales de comunicación”." ${ }^{30}$ Así, tanto la instalación como la novela comparten una estructura formal compuesta por diversos sistemas de signos, cuyo particular diseño en uno y otro caso da origen a una narrativa cartográfica anclada en el cuerpo, mediante la cual, como se anotó, se articula una relación cuerpo-espacio.

\title{
La relación cuerpo-espacio en Signos cardinales y En el brazo del río
}

\author{
El cuerpo [...]; sus límites, definiciones, intercambios con el mundo, subordinación, placeres, dolores y \\ destrucción sirven para escribir el texto social. \\ Carlos A. Jáuregui y Juan Pablo Dabove
}

Uno de los vínculos más evidentes entre el cuerpo y el espacio en Signos cardinales se observa en el hecho de que las piernas sean el soporte de los mapas. La corporalidad salta a la vista gracias a la desnudez de cada uno de los miembros inferiores, retratados desde las rodillas hacia abajo, incluso los pies en toda su extensión. Algunas condiciones físicas sobresalientes son las venas varicosas, las cicatrices o las deformidades digitales tipo hallux valgus, conocidas como juanetes. En la mayoría de las fotografías, se observan las uñas despintadas y la diversidad del color de la piel. Tales condiciones denotan el carácter colectivo del fenómeno del desplazamiento. Del mismo modo, la exposición de los pies desnudos, plantados de frente, y la ausencia de los rostros, no solo simboliza el anonimato, el despojo, el destierro, la experiencia singular/colectiva o las condiciones de pobreza y abandono que enfrentan la mayoría de los desplazados, sino que puede verse como un elemento transgresor, que genera extrañeza, entre otras razones, porque con la toma exclusiva de las pierna se traspasan los límites estéticos de la fotografía, interesada en captar imágenes más armoniosas y bellas que podrían lograrse al retratar el cuerpo completo o por lo menos la cara, y así configurar un sentido abyecto en los términos planteados por Kristeva: "aquello que perturba una identidad, un sistema, un orden. Aquello que no respeta los límites, los lugares, las reglas". ${ }^{31}$ De esta forma, se puede comprender la posibilidad implícita que lleva la abyección en sí misma de ejercer contraposición al orden establecido. La dimensión estética que incluye lo abyecto adquiere así un carácter político.

29 J. Brian Harley, "Texts and Contexts in the Interpretation of Early Maps", en The New Nature of Maps: Essays in the History of Cartography, ed. por Paul Laxton (Baltimore: The Johns Hopkins University Press, 2001), 36.

30 "Like all other texts, maps use signs to represent the world. [...]. Maps do not possess a gramar in the mode of written language, but they are nonetheless deliberately designed texts, created by the aplication of principles and techniques and developed as formal systems of comunication". Cf. Harley, "Texts and Contexts in the Interpretation of Early Maps", 36.

31 Julia Kristeva, Poderes de la perversión (México: Siglo XIX, 1988), 11. 
La configuración de dicho carácter político también tiene que ver con la representación que se hace en la obra tanto de la memoria personal como de la emotividad y del sentir de quienes debieron abandonarlo todo de forma intempestiva, en algunos casos, varias veces; de ahí que los mapas elaborados sobre las piernas representen la centralidad que adquiere el cuerpo para los desplazados y puedan "ser entendido[s] como la enunciación de uno[s] sujeto[s]".32 Así pues, "la subjetividad cobra un rol activo para configurar caminos que no aparecen en las cartografías institucionalizadas". ${ }^{33}$

De igual manera, las convenciones participan en la delimitación de la relación cuerpo-espacio y su vínculo con la violencia. Entre ellas, solo se van a mencionar tres. Los "Centros religiosos o históricos": estructuras con dos cúpulas, una más alta que la otra, y una cruz sobre la primera, en su totalidad pintadas de negro. Dicha imagen resulta significativa, pues, de hecho, durante el conflicto armado colombiano, las iglesias han sido transformadas con frecuencia en refugios para las comunidades desplazadas, incluso, se han cometido masacres ${ }^{34}$ dentro de ellas, por lo que se han cargado de memoria histórica, de ahí que en la instalación estas figuras trasciendan el papel de meros referentes espaciales. Las convenciones que simbolizan sitios probables de ocurrencia de masacres, mediante pequeños grupos de cruces, $o$ aquellas que simbolizan zonas con alta sospecha de campos minados, mediante un círculo con una cruz encima, también se encuentran cargadas de memoria histórica no solo de la multiplicidad de masacres perpetradas o del sinnúmero de regiones afectadas por campos minados a lo largo del territorio nacional, sino de los propios cuerpos pertenecientes a las víctimas de la violencia durante el conflicto armado, a la cual aluden las mencionadas convenciones.

De forma similar a lo que se evidencia en la instalación, la estructura narrativa de En el brazo del río, así como el mismo título, se sitúan, se anclan en la corporalidad, la experiencia y la memoria, en este caso, de los personajes, Paulina y Sierva María, que prestan su voz para dar testimonio de sus respectivas historias de vida, y de muerte, vinculadas a diversos acontecimientos de violencia. Sin embargo, es Paulina quien vivencia en carne propia las consecuencias de la guerra establecida en su región de origen. Uno de los pasajes en los que mejor se expresa el carácter experiencial de la narración, ligado al cuerpo, a la emotividad, a la territorialidad y a la memoria se encuentra al principio de la obra, cuando Paulina, además de aludir al lugar desde donde se ubica para narrar, realiza un viaje por su pasado, como lo hará en el transcurso de la novela, y se ubica en el día que inicia el último de los itinerarios de su vida.

Hoy sé que sí existe la eternidad. Y no es el lugar desde el que estoy contando, sino las largas horas que transcurrieron entre la noche del martes doce de enero y el amanecer del miércoles trece. La eternidad es un grito que nunca fue escuchado, es la voz que no sale, es el corazón que late desbocado, son las piernas que tiemblan y no sostienen, es el miedo que seca la boca, es desear que todo termine de una vez y para

32 Diego Nicolás Massariol, "Operaciones enunciativas de subjetivación en el discurso de la cartografía artística actual como estrategia de dialogicidad y contra-conducta”, AdVersus: Revista de Semiótica, no. 31 (2016): 148.

33 Massariol, "Operaciones enunciativas de subjetivación en el discurso", 158.

34 El 2 de mayo de 2002, las Fuerzas Armadas Revolucionarias de Colombia (FARC) lanzaron un cilindro de gas cargado con dinamita que cayó en la capilla de San Pablo Apóstol de Bellavista, la principal zona urbana de Bojayá (Chocó). Dentro de la capilla se encontraban unas trescientas personas que se protegían del ataque guerrillero, y más de cien de esas personas murieron ese día en la iglesia; cf. Armando Neira, “¿Cómo fue la masacre de Bojayá?", Semana, 13 de mayo de 2002, https://www.facebook.com/RevistaSemana/videos/c\%C3\%B3mo-fue-la-masacre-debojay\%C3\%A1/2788695214793684/. 
siempre. La eternidad es lo contrario a la felicidad, como la que yo tenía la mañana de ese mismo martes cuando, madrugadas, llegamos a uno de los puertos de Barrancabermeja y afanosas buscamos la canoa con motor de Honorio Vélez, para que nos llevara a La Vega, como se llamaba nuestra finca, en Vuelta Acuña [...]. Por eso, ese martes por la mañana, en el puerto, el olor a pescado fresco y una brisa que llegaba desde el frente del río, me explayaron el corazón. ${ }^{35}$

Hablar desde la eternidad es un recurso que le confiere un tono transgresor a la novela, así como una alta carga simbólica, al subvertir el silencio de los desaparecidos, condición representada por Paulina debido a que su cuerpo no será encontrado. Ubicarse desde la muerte le confiere la posibilidad a Paulina de hacer memoria de su propio cuerpo. Hablar desde la muerte también implica que Paulina asuma la posición de narradora omnisciente, lo que le permitirá contrariar la memoria oficial ofrecida por los artículos de prensa sobre lo acaecido durante la masacre. Por último, hablar desde la muerte indica la resistencia que opone Paulina a ser reducida a la condición de cuerpo-objeto sufriente a la cual se llega por efecto de la extrema violencia, como el abuso sexual al que es sometida Paulina por la mayoría de sus captores.

En la cita, también puede verse cómo en la novela, al igual que en la instalación, se nombran determinadas regiones del país. Aunque en este caso los referentes geográficos se circunscriben al Magdalena Medio, entre Puerto Berrío (Antioquia) y Barrancabermeja (Santander), por cuyas riberas corre el río Magdalena, afluente por donde transitan peces, lanchas, mercancías y personas, pero también el sinnúmero de muertos producto de la guerra, entre los que posiblemente se encuentra la misma Paulina, como lo menciona su amiga Sierva María: "El cuerpo de Paulina Lazcarro nunca fue encontrado. Yo pienso que quedó en el buche de los gallinazos o, por qué no, que se enterró en el fondo del río y alimentó a los coroncoros". ${ }^{36}$ Así que no es fortuita la delimitación que se hace en ambas obras de ciertas regiones, como ocurre en el caso del Magdalena Medio, ${ }^{37}$ zona de la cual en la instalación se representa su "epicentro regional", ${ }^{38}$ a través de la palabra Barranca en uno de los mapas. Entre las razones que pueden estar involucradas en tal delimitación, es que se trata de una las regiones de mayor afectación durante la década de 1980 por causas relacionadas con el conflicto armado, debido al auge del paramilitarismo en ese lapso temporal.

\section{Pasos despojados que reescriben las fronteras}

En cuanto a la magnitud del desplazamiento, en la instalación se narra, a través de los itinerarios, la multiplicidad de regiones afectadas, que incluyen tanto áreas rurales de veredas o corregimientos como

35 Sandoval, En el brazo del río, 19.

36 Sandoval, En el brazo del río, 13.

37 "El Magdalena Medio abarca buena parte del centro de Colombia, unos $400 \mathrm{Km}$. del curso medio del río Magdalena, está conformada por varios municipios de los departamentos de Bolívar, Cesar, Magdalena, Antioquia, Caldas, Cundinamarca, Boyacá, Santander y Norte de Santander, siendo sus principales ejes económicos y políticos sociales: Puerto Berrío en Antioquia; la Dorada Caldas; Boyacá, Puerto Boyacá y Barrancabermeja Santander, además del eje militar de la Base Palanquero en Cundinamarca (Puerto Salgar) y el Batallón antiaéreo Nueva Granada en Barranca"; cf. Ismael Paredes, "Magdalena Medio, un sueño de vida en medio de la guerra", https://www.alainet.org/ es/articulo/143541.

$38 \mathrm{CNMH}$, Nuevos escenarios del conflicto armado y violencia (Bogotá: CNMH, 2014), 44. 
urbanas de Medellín, Bucaramanga, Cúcuta, Bogotá o Pasto. La presencia de tales ciudades representa el usual tránsito del campo a los centros urbanos que realizan los desplazados en Colombia. Entre las regiones representadas en la instalación, se encuentra otra de las más afectadas durante el conflicto armado, la del Urabá antioqueño, con municipios como Apartadó, Turbo, Mutatá o Necoclí.

En la novela, también se relata la magnitud del desplazamiento, así se enmarque en una región específica. Barrancabermeja se constituye en el lugar de llegada de la mayoría de los campesinos desplazados de la vereda Vuelta Acuña luego de la masacre: en palabras de Sierva María, "ya eran cerca de tres mil los campesinos que se encontraban en el puerto petrolero, como acostumbraban llamar a la ciudad", "h9 "habían abandonado sus parcelas y se negaban a retornar a ellas. Aseguraban que la muerte había empezado a bajar en lancha desde Puerto Berrío". 40 Sierva María no solo alude a la gran cantidad de personas que se ven obligadas a salir forzadamente de sus respectivas parcelas, sino que señala el peligro que representa Puerto Berrío, pues allí se encuentran los grupos armados que ejercen control sobre la región. Señalamientos como este funcionan casi de la misma manera en que lo hacen las convenciones que marcan las zonas con alta sospecha de campos minados o de masacres en la instalación, pues indican los lugares amenazantes para la comunidad. Así es como puede decirse que tanto en la instalación como en la novela se reconstruye de manera crítica el texto social del desplazamiento y de otros tipos de violencia corporal propias del conflicto armado. Dicho texto bien puede leerse/visualizarse como un "libro de historia", ${ }_{41}$ elaborado a partir de un mapa geográfico.

Si bien en la novela el éxodo de campesinos se realiza dentro de los márgenes del país, en la instalación algunos de los itinerarios los sobrepasan yllegan a lugares como Santiago de Chile, Ecuador, o Barquisimeto y Caracas en Venezuela. (Ver Figura 3). En este caso, se pone en evidencia cómo las fronteras pueden ser, y han sido, "apropiadas por la vía de la expulsión y el desalojo masivo de la población desplazada", ${ }^{2}$ lo cual problematiza la capacidad estatal para brindar protección a estas comunidades. ${ }^{43}$ Por otro lado, tales recorridos permiten la visualización de un fenómeno poco reconocido en el país: el desplazamiento transfronterizo derivado de la confrontación armada. Según el Centro Nacional de Memoria Histórica (CNMH), hasta 2015 más de cuatrocientas mil personas habían solicitado refugio en otros países de América Latina por circunstancias de violencia ligadas al conflicto armado, hecho sobre el que se llama la atención debido a que más de la mitad de colombianos que lograron traspasar las fronteras no fueron reconocidos como refugiados, por lo cual permanecían "como una población flotante, invisible para los registros oficiales, principalmente en países vecinos como Venezuela, Ecuador y Panamá", ${ }^{44}$ dos de ellos mapeados en la instalación.

39 Sandoval, En el brazo del río, 72.

40 Sandoval, En el brazo del río, 73.

41 De Certeau, La invención de lo cotidiano, 133.

42 Adriana González Gil, "Del desplazamiento forzado interno en Colombia a la migración transfronteriza hacia Ecuador", Estudios Políticos, no. 47 (2015): 189.

43 En cuanto a la ineficiencia del Estado colombiano ante el desplazamiento masivo, el CNMH menciona que, a pesar de la implementación estatal de un marco legal para proteger a las víctimas, no se ha logrado ni proteger ni prevenir a la población de tal fenómeno.

44 CNMH, Una nación desplazada (Bogotá: CNMH, 2015), 26. 
Figura. 3.

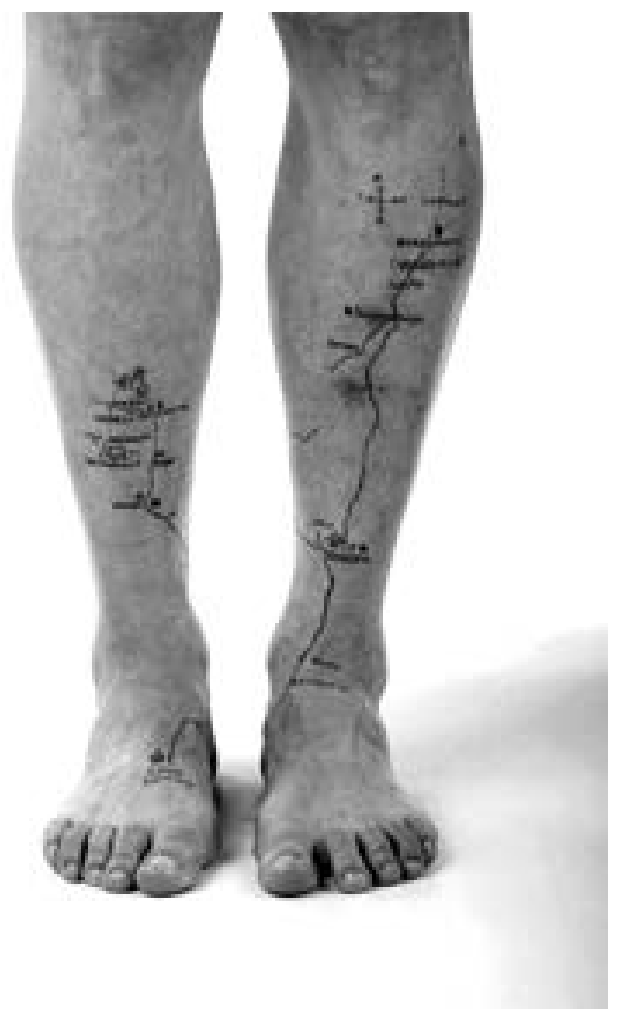

Fuente: Libia Posada. “Signos Cardinales”. Cuadernos de música, artes visuales y artes escénicas 9, no. 2 (2014): 219. Fotografía. 100 x $80 \mathrm{~cm}$. https://revistas.javeriana.edu.co/index.php/cma/article/view/13072/10411.

Así, para quienes se ven obligados a salir del país por la violencia fruto del conflicto armado, su condición de desplazados ${ }^{45}$ se trasmuta a la de refugiados, figura problemática, pues, como lo señala Agamben, ${ }^{46}$ al perder la investidura de la ciudadanía, el refugiado se expone en cuanto nuda vida, es decir, en cuanto ser viviente, pero desprovisto de sus derechos civiles. ${ }^{47}$ Según Bauman, "Los refugiados [...] son 'la encarnación

45 La condición de desplazados se les adjudica a quienes deben abandonar sus bienes por condiciones de violencia, pero no llegan a traspasar las fronteras de su país. Mientras que "un refugiado es [...] aquella persona que debe abandonar su lugar de origen o residencia por culpa de la guerra o que es perseguido por motivos de raza, religión, nacionalidad u orientación sexual, entre otros. En su huida, deja atrás todo lo que tiene y cruza las fronteras de su país, asentándose generalmente en regiones fronterizas [...]”; cf. ACNUR, “¿En qué se diferencia un desplazado de un refugiado?”, https://eacnur.org/blog/en-que-se-diferencia-un-desplazado-de-un-refugiado/.

46 "Si los refugiados [...] representan, en el orden del Estado-nación moderno, un elemento tan inquietante, es, sobre todo, porque, al romper la continuidad entre hombre y ciudadano, entre nacimiento y nacionalidad, ponen en crisis la ficción originaria de la soberanía moderna. Al manifestar a plena luz la separación entre nacimiento y nación, el refugiado hace comparecer por un momento en la escena política la nuda vida que constituye el presupuesto secreto de ella"; cf. Giorgio Agamben, "El campo de concentración como paradigma biopolítico de lo moderno", en Homo sacer: El poder soberano y la nuda vida, trad. por Antonio Gimeno Cuspinera (Valencia: Pre-Textos, 2010), $166-167$.

47 Agamben, “El campo de concentración como paradigma biopolítico de lo moderno”, 167. 
de los forasteros' [...], forasteros en todas partes y fuera de lugar en todas partes salvo en lugares que están ellos mismos fuera de lugar: los 'lugares en ninguna parte' que no aparecen en ninguno de los mapas usados en sus viajes por los seres humanos normales y corrientes".48 De esta forma, los refugiados representarían la condición de seres anormales o desviantes y, por eso mismo, los espacios que ocupan, la de heterotopías, en los términos planteados por Foucault: "lugares que suspenden, neutralizan o invierten el conjunto de relaciones que se hallan por ellos designadas, reflejadas o reflectadas". ${ }^{49}$ Es decir, que se trata de espacios que representan en sí mismos la contravención o contienen aquello que controvierte las normas o modelos alrededor de los cuales se articula el conjunto de relaciones que los definen.

En este sentido, en la instalación y en la novela, se alude al desvío impuesto a los desplazados en Colombia, reflejado en hechos relacionados con verse obligados a ubicarse en lugares de invasión de las ciudades, ganarse el sustento diario mendigando en los semáforos y medios de transporte, o en no tener acceso ni a la educación ni a la salud. Puede sostenerse, entonces, que en ambas obras se desdibuja, aludiendo a Nancy Appelbaum, aquella nación que circula en los mapas oficiales de Colombia, se delinea un país otro, desconocido, para la parte de la población que percibe desde la distancia el desplazamiento y las demás formas de violencia empleadas por los diversos actores armados existentes en el país.

\section{Conclusiones}

A manera de conclusión se puede decir que las obras analizadas les expresan a sus espectadores y lectores, por medio de las piernas y los pies desnudos de las personas desplazadas, así como de las voces adolescentes de Paulina y Sierva María, que los itinerarios del desplazamiento continúan vigentes, es más, que a la par con el aumento de la cantidad de desplazados, se va configurando un país alterno del despojo y el desarraigo paralelo al que intenta encarrilarse por la vía del desarrollo. De este modo, se pone de manifiesto la postura crítica responsable de articular cada una de las obras, gracias a la cual, en vez de caer en la espectacularización del desplazamiento forzado, las dos obras "asegura[n] un lugar enunciativo válido" ${ }^{50}$ para la reconstrucción de la memoria histórica del conflicto armado, que debería incluir la multiplicidad de narrativas que la componen, y la toma de un "posicionamiento para sentar una denuncia [...] hacia el Estado central y las instituciones que deberían velar por la protección y el respeto de los derechos humanos". ${ }^{51}$

Tal vez haga falta prestar mayor atención a esas narrativas configuradas a partir del arte o la literatura, pues hacerlo podría contribuir con la superación de las fronteras que separan a los miembros de la sociedad colombiana y, en ese sentido, se podría generar mayor empatía por el sufrimiento y los problemas que aquejan a las víctimas de la confrontación armada del país.

48 Zygmunt Bauman, Vidas desperdiciadas: La modernidad y sus parias, trad. por Pablo Hermida Lazcano (Buenos Aires: Paidós, 2005), 106.

49 Michel Foucault, “Espacios otros”, Architecture, mouvement, continuité, no. 5 (1984): 18.

50 Jorge Andrés Cárdenas Santamaría, "Representación narrativa de la violencia y el conflicto armado en la obra En el brazo del río de Marbel Sandoval”, Cuadernos de Literatura, no. 26 (2017): 98.

51 Cárdenas Santamaría, "Representación narrativa de la violencia”, 101. 


\section{Bibliografía}

ACNUR (Alto Comisionado de las Naciones Unidas para los Refugiados). “¿En qué se diferencia un desplazado de un refugiado?”. https://eacnur.org/blog/en-que-se-diferencia-un-desplazado-de-un-refugiado/

Acosta, María del Rosario y Laura Quintana. "De la estetización de la política a la comunidad desobrada". Revista de Estudios Sociales, no. 35 (2010): 53-65. https://doi.org/10.7440/res35.2010.05

Agamben, Giorgio. "El campo de concentración como paradigma biopolítico de lo moderno". En Homo sacer: El poder soberano y la nuda vida. Traducido por Antonio Gimeno Cuspinera, 151-181. Valencia: Pre-Textos, 2010.

Bauman, Zygmunt. Vidas desperdiciadas: La modernidad y sus parias. Traducido por Pablo Hermida Lazcano. Buenos Aires: Paidós, 2005.

Benjamin, Walter. La obra de arte en la época de su reproductibilidad técnica. Traducido por Andrés E. Weikert. México: Ítaca, 2003.

Blair, Elsa. “¿Nuevas guerras? ¿Nuevos espacios para la guerra? O ¿Nuevas espacialidades?”. En (Des) territorialidades y (no) lugares: Procesos de configuración y transformación social del espacio, editado por Diego Herrera Gómez y Carlo Emilio Piazzini Suárez, 135-152. Medellín: La Carreta, 2006.

Blair, Elsa. "La política punitiva del cuerpo: 'Economía del castigo' o mecánica del sufrimiento en Colombia". Estudios Políticos, no. 36 (2010): 39-66.

Careri, Francesco. Walkscapes: El andar como práctica estética. Traducido por Maurici Pla. Barcelona: Gustavo Gili, 2002.

Cárdenas Santamaría, Jorge Andrés. "Representación narrativa de la violencia y el conflicto armado en la obra En el brazo del río de Marbel Sandoval". Cuadernos de Literatura, no. 26 (2017): 87-102.

Certeau, Michel de. La invención de lo cotidiano. Vol. 1: Artes de hacer. Traducido por Alejandro Pescador. México: Universidad Iberoamericana, 2000.

CNMH (Centro Nacional de Memoria Histórica). Nuevos escenarios del conflicto armado y violencia. Bogotá: $\mathrm{CNMH}, 2014$.

CNMH (Centro Nacional de Memoria Histórica). Una nación desplazada. Bogotá: CNMH, 2015.

Fenves, Peter. “¿Existe una respuesta a la estetización de la política?”. En Walter Benjamin: Culturas de la imagen, compilado por Alejandra Uslenghi, 75-97. Buenos Aires: Eterna Cadencia, 2010.

Foucault, Michel. "Espacios otros". Architecture, mouvement, continuité, no. 5 (1984): 15-26.

González Gil, Adriana. "Del desplazamiento forzado interno en Colombia a la migración transfronteriza hacia Ecuador”. Estudios Políticos, no. 47 (2015): 177-197. https://doi.org/10.7440/res35.2010.05

Gutiérrez Peláez, Miguel y Flor Ángel Rincón. "Trayectos entre estética y biopolítica: Trauma, sujeto e imagen”. (Pensamiento), (palabra) y obra, no. 7 (2012): 42-55. https://doi.org/10.17227/ppo.num7-1423

Harley, J. Brian. "Texts and Contexts in the Interpretation of Early Maps". En The New Nature of Maps: Essays in the History of Cartography, editado por Paul Laxton, 33-49. Baltimore: The Johns Hopkins University Press, 2001.

Kristeva, Julia. Poderes de la perversión. México: Siglo XIX, 1988.

Massariol, Diego Nicolás. “Operaciones enunciativas de subjetivación en el discurso de la cartografía artística actual como estrategia de dialogicidad y contra-conducta”. AdVersus: Revista de Semiótica, no. 31 (2016): 141-165.

Massey, Doreen. "Espacio, lugar y política en la coyuntura actual". Urban: Revista del Departamento de Urbanística y Ordenación del Territorio, no. 4 (2012): 7-12.

Molano Osorio, Ingrid Vanessa. "Signos cardinales de Libia Posada y En el brazo del río de Marbel Sandoval: La resignificación del cuerpo a través de una narrativa cartográfica”. Tesis de maestría, Universidad de los Andes, 2019. https://repositorio.uniandes.edu.co/handle/1992/48459.

Neira, Armando. “Cómo fue la masacre de Bojayá?”. Semana, 13 de mayo de 2002. https://www.facebook.com/ RevistaSemana/videos/c\%C3\%B3mo-fue-la-masacre-de-bojay\%C3\%A1/2788695214793684/

Oslender, Ulrich. "Des-territorialización y desplazamiento forzado en el Pacífico colombiano: La construcción de 'geografías de terror'”. En (Des) territorialidades y (no) lugares: Procesos de configuración y transformación social del espacio, editado por Diego Herrera Gómez y Carlo Emilio Piazzini Suárez, 155-172. Medellín: La Carreta, 2006.

Paredes, Ismael. "Magdalena Medio, un sueño de vida en medio de la guerra". https://www.alainet.org/es/ articulo/143541. 
Piazzini Suárez, Carlo Emilio. "El tiempo situado: Las temporalidades después del 'giro espacial'". En (Des) territorialidades y (no) lugares: Procesos de configuración y transformación social del espacio, editado por Diego Herrera Gómez y Carlo Emilio Piazzini Suárez, 53-73. Medellín: La Carreta, 2006.

Posada, Libia. "Signos cardinales". Cuadernos de Música, Artes Visuales y Artes Escénicas 9, no. 2 (2014): 217-222.

Sandoval, Marbel. En el brazo del río. Medellín: Hombre Nuevo, 2006.

Segato, Rita Laura. "En busca de un léxico para teorizar la experiencia territorial contemporánea". En (Des) territorialidades y (no) lugares: procesos de configuración y transformación social del espacio, editado por Diego Herrera Gómez y Carlo Emilio Piazzini Suárez, 75-94. Medellín: La Carreta, 2006. 